\title{
Effects of nutrient availability on the amphicarpic traits of Persicaria thunbergii
}

\author{
Jae Hyun Kim ${ }^{\mathrm{a}}$, Jong Min Nam ${ }^{\mathrm{c}}$, Jae Geun Kim ${ }^{\mathrm{a}, \mathrm{b}, *}$ \\ a Department of Biology Education, Seoul National University, Seoul 08826, Republic of Korea \\ ${ }^{\mathrm{b}}$ Center for Education Research, Seoul National University, Seoul 08826, Republic of Korea \\ ${ }^{\mathrm{c}}$ Research Institute for Agriculture and Life Sciences, Seoul National University, Seoul 08826, Republic of Korea
}

\section{A R T I C L E I N F O}

\section{Article history:}

Received 29 July 2015

Received in revised form 1 March 2016

Accepted 1 March 2016

Available online 3 March 2016

\section{Keywords:}

Allocation

Amphicarpy

Nutrient

Life-history strategies

\begin{abstract}
A B S T R A C T
Environmental factors affecting the expression of amphicarpic traits in Persicaria thunbergii are not well studied. We thus performed to investigate the effects of nutrients on the amphicarpic traits of $P$. thunbergii in a mesocosm experiment. Three nutrient levels were applied using different intervals between fertilization: no fertilization (low nutrient), fertilization at eight-week intervals (medium), and at four-week intervals (high). We compared the relative stem length growth rates $\left(\mathrm{RGR}_{\mathrm{ST}}\right)$ and biomass allocation of seedlings from aerial seeds (SA) and subterranean seeds (SS), and then investigated the flowering time and the seed production traits of $P$. thunbergii according to nutrient level. The results showed that RGR $\mathrm{R}_{\mathrm{ST}}$, biomass allocation and total biomass were not different between SA and SS at all levels. Aerial flowering started earlier than subterranean flowering, in contrast to other amphicarpic plants. Subterranean seed allocation and the number of subterranean seeds were stable regardless of nutrient levels whereas aerial seed allocation decreased with increasing nutrient level. The number of aerial seeds per biomass with low nutrient was significantly higher than that at other levels. P. thunbergii showed a different trait of seed production: subterranean seeds appeared to play a role in retaining the mother-site while aerial seeds can escape the site conditions at low nutrient levels. In conclusion, the reproductive strategy of $P$. thunbergii on aerial propagule was changeable but not subterranean propagule under various nutrient conditions. SA and SS were similar about growth responses. Those characteristics would increase survivability of $P$. thunbergii. Evolutionary drivers might explain the differences of life-history strategies in flowering time between the aquatic $P$. thunbergii and other arid amphicarpic plants.
\end{abstract}

(c) 2016 Elsevier B.V. All rights reserved.

\section{Introduction}

Amphicarpic plant are able to form above-ground and belowground flowers and fruits (Cheplick, 1987). Amphicarpic plants can survive under variable environmental conditions using two seed types with different modes of development, function and strategy. (1) Aerial flowers are chasmogamous and are usually cross-pollinated, resulting in seeds that are smaller and lighter than subterranean seeds. Therefore, aerial seeds appear suitable for genetic exchange and dispersal. (2) Subterranean flowers are cleistogamous and only self-pollinated, and also have fewer, larger, and heavier seeds than aerial flowers (Koller and Roth, 1964; Cheplick, 1983; Schnee and Waller, 1986; Masuda and Yahara,

\footnotetext{
* Corresponding author at: Department of Biology Education, Seoul National University, Seoul 08826, Republic of Korea.

E-mail address: jaegkim@snu.ac.kr (J.G. Kim).
}

1994; Kaul et al., 2000; Barker, 2005). Subterranean seed production evolved independently in phylogenetically diverse taxa, and the relevant selective pressure can be different among species (Cheplick, 1987). The specific responses of amphicarpic plants to disturbances depend on the species and environmental variables. Thus, to fully understand the amphicarpic trait as an adaptive strategy, more information about specific amphicarpic responses of diverse plants under various environments situations is needed.

Persicaria thunbergii (Siebold \& Zucc.) H. Gross belongs to the Polygonaceae and is an annual amphicarpic plant, easily occupying wetland areas such as riparian zones and lakesides (Kawano, 2008; Kim et al., 2012). P. thunbergii has similar characteristics to other amphicarpic plants. The aerial flowers, which develop at the tips of shoot, are usually chasmogamous and the subterranean flowers, which develop at the tips of decumbent stem toward the ground, are cleistogamous (Kawano et al., 1990; Suzuki et al., 2007).

The environment affects the nutrient allocation pattern (Brouwer, 1962; Bloom et al., 1985). In addition, the capability 
of plants to obtain nutrients is determined by allocation patterns, competition with other species and seed production (Abrahamson and Gadgil, 1973; Tilman, 1988; Poorter et al., 1990; Schmid and Weiner, 1993; Grime, 2006). Overall, the most important concept in plant life-history theory is resource allocation (Gadgil and Bossert, 1970; Iwasa and Roughgarden, 1984; Gedroc et al., 1996). Earlier studies on $P$. thunbergii dealt with various environmental factors that affect the population, such as light, which affects allocation patterns and seed outputs (Kawano et al., 1990), as well as flooding, which influences plant height and biomass (Kim et al., 2013). A mesocosm experiment on flooding and physical damage determined that $P$. thunbergii changed the allocation to aerial seeds and subterranean seeds (Choo et al., 2014). Especially, Choo et al. (2015) reported that seedlings from subterranean seeds (SS) in the early life history would have greater ability to escape water-logged and shaded conditions and an advantage in retaking the mother-site because of higher and faster germination rates than seedlings from aerial seeds (SA). Thus, they suggested that different seedling types would have different allocation patterns under unfavorable conditions. In addition, Choo et al. (2014) suggested that $P$. thunbergii has a reproductive strategy distinct from those of other amphicarpic plants. Accordingly, P. thunbergii would not fully satisfy the pessimistic strategy observed in other amphicarpic plants, in which the productivity of subterranean seeds decreases when flooding occurs.

In this study, we aimed to understand the amphicarpic traits of $P$. thunbergii under different soil nutrient conditions. The hypotheses are that 1) the leaf, stem, root and seed biomass allocation of two types of seedlings would differ according to nutrient levels, 2) flowering time would be faster under high nutrient conditions, and aerial flowering would be faster than subterranean flowering, 3) aerial seeds would be more productive per biomass at poor nutrient conditions to facilitate dispersal, and 4) aerial seeds exhibited a plastic reproductive allocation at different nutrient conditions, different to that found in subterranean seeds.

\section{Methods}

\subsection{Nutrient conditions}

The experiment was conducted outdoors at Seoul National University, Korea from May to November 2014. The average temperature was $19.8 \pm 6.3^{\circ} \mathrm{C}$ during the experimental period. Thirty oval rubber pots $(70 \mathrm{~cm} \mathrm{~W} \times 100 \mathrm{~cm} \mathrm{~L} \times 35 \mathrm{~cm} \mathrm{H})$ were filled to a depth of $5 \mathrm{~cm}$ with sandy soil. Fertilization was performed using $5 \mathrm{~g}$ of an 18:2:10 (N:P:K) solid fertilizer (Dongbu-Hannong, Korea). The low nutrient level was soil without fertilizer addition. Medium and high nutrient levels were achieved by macronutrient addition every 4 or 8 weeks. Microelement fertilizer (Plant Nutrition Res. Inst., Daeyu, Korea) containing boron (2\%), zinc (0.6\%), manganese $(0.4 \%)$, copper $(0.05 \%)$, iron $(0.1 \%)$ and molybdenum $(0.0005 \%)$ was performed once in September.

Ninety subterranean seedlings and 90 aerial seedlings of similar stem length (SA: $5.0 \pm 1.1 \mathrm{~cm}$, SS: $5.0 \pm 0.6 \mathrm{~cm})(p=0.831)$ were selected, and three subterranean seedlings and three aerial seedlings were planted in a pot on 15 May (Fig. 1). We supplied distilled water; the water level was maintained at a depth of no more than $3 \mathrm{~cm}$ through drainage via a hole drilled at the appropriate height.

\subsection{Measurement}

Stem length was measured biweekly from 15 May to 30 June. We evaluated the blooming time for each condition every day. At the beginning of flowering, we installed a net at $15 \mathrm{~cm}$ above

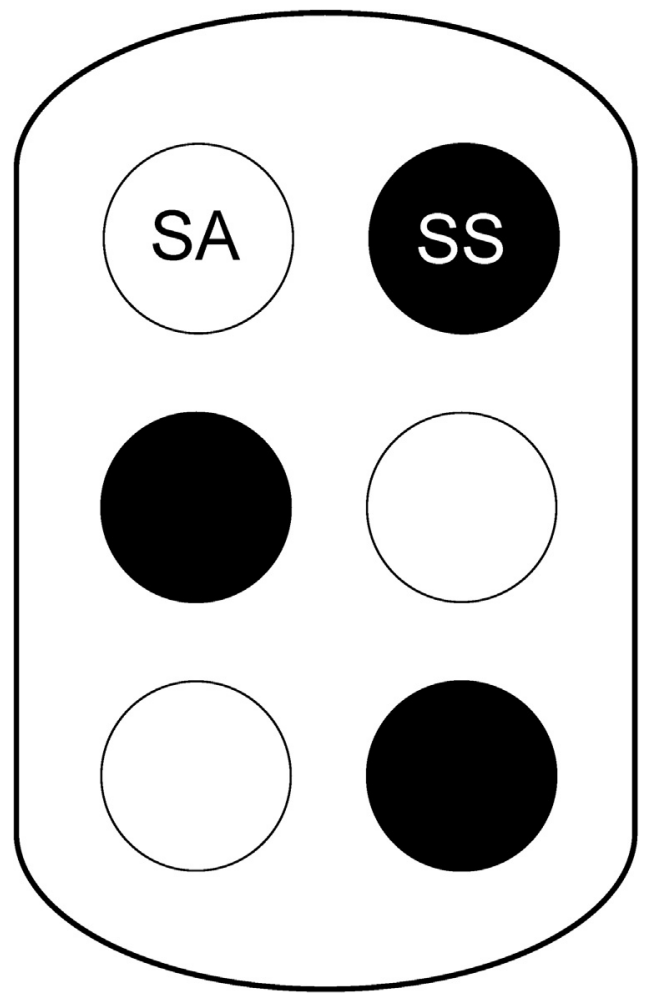

Fig. 1. Diagram of seedling arrangement in pot. SA, seedling from aerial seed. SS, seedling from subterranean seed.

the soil to separate aerial from subterranean seeds. Subterranean flowering was observed as the growth of the tip of the creeping stem of up to $10-15 \mathrm{~cm}$ on the soil. Harvesting was performed twice: on 25 July with 15 pots ( 5 pots per nutrient level) and on 3 November, when the plant foliage had withered, with 15 pots. The plants harvested on 25 July (first harvest) were separated into three organ parts (leaf, root and stem) and those are assorted again as seedling from subterranean and aerial seed. For the second harvest, plants were separated into four organs (leaf, root, stem and seed). Aerial seeds were gathered from the net, and subterranean seeds from soil. Finally, the organs were dried in an oven for $48 \mathrm{~h}$ at $80^{\circ} \mathrm{C}$. We calculated relative stem length growth rates $\left(\mathrm{RGR}_{\mathrm{st}}\right)$ $(\mathrm{cm} /$ day $)=\left(\ln x_{2}-\ln x_{1}\right) /\left(t_{2}-t_{1}\right)$, where $x_{1}$ is the stem length at $t_{1}$ time and $x_{2}$ is the stem length at $t_{2}$ time. To evaluate biomass allocation, we used stem mass fraction (SMF), leaf mass fraction (LMF) and root mass fraction (RMF) (SMF or LMF or RMF = stem or leaf or root dry mass/total dry mass; $\left.\mathrm{g} / \mathrm{g}^{-1}\right)$. As a reproductive allocation pattern, we calculated aerial seed allocation, subterranean seed allocation $\left(\mathrm{g} / \mathrm{g}^{-1}\right)$ (aerial or subterranean allocation $=$ aerial or subterranean seed dry mass/total biomass).

\subsection{Analysis of soil nutrient}

Soil was sampled 1 week after each fertilization and sieved using a $2 \mathrm{~mm}$ mesh sieve. $\mathrm{NO}_{3}-\mathrm{N}$ and $\mathrm{NH}_{4}-\mathrm{N}$ in soil were extracted with a $2 \mathrm{M} \mathrm{KCl}$ solution (Kim et al., 2004), and $\mathrm{PO}_{4}-\mathrm{P}$ was extracted with Bray No. 1 solution (Bray and Kurtz, 1945). $\mathrm{NO}_{3}-\mathrm{N}, \mathrm{NH}_{4}-\mathrm{N}$, and $\mathrm{PO}_{4}$ $\mathrm{P}$ in water and in the extracted soil solution were analyzed by the hydrazine method (Kamphake et al., 1967), indo-phenol method (Murphy and Riley, 1962), and ascorbic acid reduction method (Solorzano, 1969), respectively. 


\subsection{Statistical analysis}

Data were statistically analyzed using the statistical software environment $\mathrm{R}$ ( $\mathrm{R}$ Development Core Team, 2014) for two-way ANOVA and one-way ANOVA with post hoc test Tukey HSD (honestly significant difference) and PERMANOVA with 999 permutations. The reproduction allocation data were log-transformed and evaluated by ANOVA with Tukey's post hoc HSD test. Differences in soil nutrient levels from May to September were assessed using repeated measured ANOVA with Greenhouse-Geisser to adjust degrees of freedom. In addition, we used the pair-wise permutational $t$-test after PERMANOVA. Standardized major axis (SMA) regression was used to describe the relationship between each combination of traits in seedlings from aerial and subterranean seeds after log-transformation. The SMA method is appropriate when the purpose of the study is to describe the relationships between variables (Warton et al., 2006).

\section{Results}

\subsection{Changes in soil nutrient conditions}

Before treatment, the $\mathrm{NH}_{4}-\mathrm{N}, \mathrm{NO}_{3}-\mathrm{N}$, and $\mathrm{PO}_{4}-\mathrm{P}$ levels were $2.9 \pm 0.7,1.7 \pm 0.5$, and $24.5 \pm 1.7 \mathrm{mg} / \mathrm{kg}$, respectively (Fig. 2). The $\mathrm{PO}_{4}-\mathrm{P}$ level decreased significantly during the experiment (repeated measured ANOVA, $\mathrm{F}_{4,24}=4.050, p=0.012$ ). There was no interaction between nutrient levels and time $\left(F_{8,24}=1.126\right.$, $p=0.382$ ). There was no significant difference between nutrient levels $\left(F_{2,6}=0.047, p=0.955\right)$. The $\mathrm{NO}_{3}-\mathrm{N}$ level decreased significantly during the experiment (repeated measures ANOVA, Greenhouse-Geisser adjusted $\mathrm{F}_{1.16,6.93}=56.067, p=0.004$ ). There was an interaction between nutrient levels and time (GreenhousGeisser adjusted $F_{2.31,6.93}=8.493, p=0.012$ ). Nutrient levels differed significantly $\left(\mathrm{F}_{2,6}=30.876, p=0.001\right)$. The $\mathrm{NH}_{4}-\mathrm{N}$ level decreased significantly during the experiment (repeated measured ANOVA, Greenhouse-Geisser adjusted $F_{1.46,8.77}=19.262, p=0.001$ ). There was an interaction between nutrient levels and time (GreenhouseGeisser adjusted $F_{2.92,8.77}=3.960, p=0.05$ ). There was no significant difference between nutrient levels $\left(F_{2,6}=2.692, p=0.146\right)$.

\subsection{Growth responses to mutrient}

The $\mathrm{RGR}_{\mathrm{ST}}$ was not different between seedling types but was affected by nutrient levels. $\mathrm{RGR}_{\mathrm{ST}}$ in May differed significantly between high and medium-low level (two-way ANOVA, $\mathrm{F}_{2,174}=53.04, p<0.02$ ), but not between seedling types $\left(F_{1,174}=0.010, p=0.919\right)$, and there was no interaction between nutrient level and seedling type $\left(F_{2,174}=0.016, p=0.852\right)$. $R_{S R} R_{S T}$ in June was significantly different among the nutrient levels (twoway ANOVA, $\mathrm{F}_{2,174}=46.812, p<0.001$ ), but there was no significant difference between seedling types $\left(\mathrm{F}_{1,174}=0.067, p=0.796\right)$, and no significant interaction between nutrient level and seedling type $\left(F_{2,174}=0.119, p<0.888\right)$.

The mean total biomass of SA and SS in late July was $1.11 \pm 0.77 \mathrm{~g}$ and $1.03 \pm 0.80 \mathrm{~g}$ under low-nutrient conditions, $12.49 \pm 5.81 \mathrm{~g}$ and $11.35 \pm 5.96 \mathrm{~g}$ under medium nutrient conditions, and $22.66 \pm 7.02 \mathrm{~g}$ and $27 \pm 8.03 \mathrm{~g}$ under high-nutrient conditions, respectively. There was no significant difference between seedling types (PERMANOVA, $\mathrm{F}_{1,86}=0.77, p=0.391$ ) and no significant interaction between nutrient levels and type $\left(F_{2,86}=2.13, p=0.127\right)$, but there were significant differences among nutrient levels $\left(F_{2,86}=205.49, p<0.001\right)$.

For the LMF of high, medium and low nutrient levels, the individual slopes for SA and SS were not significantly different (high: $p=0.30$, medium: $p=0.94$, low: $p=0.60$ ) and negatively corre-
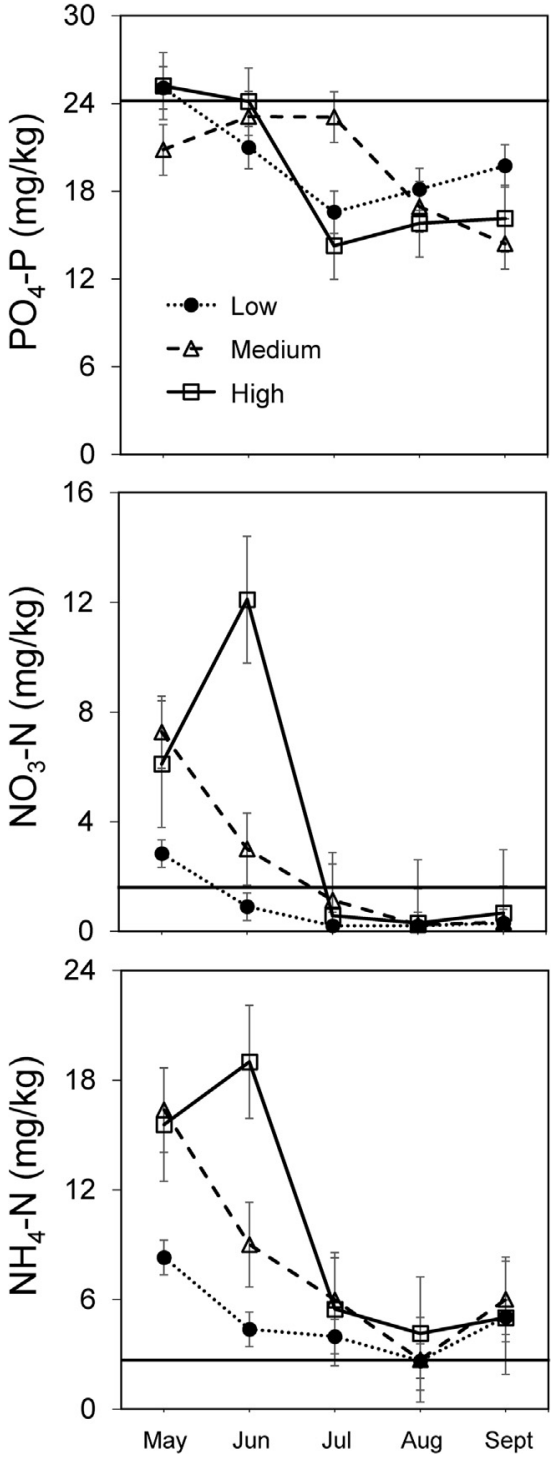

Fig. 2. Changes in soil nutrient contents. Horizontal solid line (-), initial soil nutrient condition.

lated with total biomass (high: common slope $=-1.48$, medium: common slope $=-2.74$, low: common slope $=-2.75)($ Table 1$)$. LMF differed significantly between nutrient levels (two-way ANOVA, $\mathrm{F}_{2,84}=14.771, p<0.0001$ ) but not between seedling types $\left(F_{1,84}=0.191, p=0.664\right)$, and there was no interaction between nutrient level and seedling type $\left(F_{2,84}=0.726, p=0.485\right)$ (Table 3$)$.

For RMF at high, medium and low nutrient levels, the individual slopes for SA and SS were not significantly different (high: $p=0.98$, medium: $p=0.98$, low: $p=0.32$ ) and positively correlated with total biomass (high: common slope $=1.83$, medium: common slope $=2.27$, low: common slope $=1.56)$ (Table 1$)$. RMF was not significantly different between seedling types (PERMANOVA, $\mathrm{F}_{1,84}=1.746, p=0.177$ ), but was significantly different between nutrient levels $\left(F_{2,84}=5.400, p<0.001\right)$. There was no interaction between seedling type and nutrient level $\left(F_{2,84}=1.239, p=0.308\right)$.

For SMF at the high, medium and low nutrient levels, the individual slopes for SA and SS were not significantly different (high: $p=0.51$, medium: $p=0.29$, low: $p=0.41$ ). SMF at the high and medium levels was positively correlated with total biomass (high: common slope $=2.60$, medium: common slope $=4.83$ ) but at the low level was negatively correlated with total biomass (common slope $=-3.69$ ). SMF was not significantly different between 
Table 1

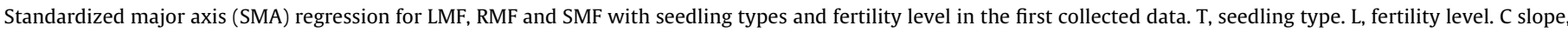
common slope. $\mathrm{C} i, 95 \%$ confidence interval.

\begin{tabular}{|c|c|c|c|c|c|c|c|c|}
\hline Trait $Y(X)$ & $\mathrm{T}$ & $\mathrm{L}$ & Slope & $r^{2}$ & SMA Pval & $\mathrm{Ci}$ & & C slope \\
\hline \multirow{6}{*}{$\begin{array}{l}\text { LMF } \\
\text { (total biomass) }\end{array}$} & SA & High & -0.083 & 0.023 & 0.30 & -2.14 & -1.03 & -1.48 \\
\hline & SS & & -0.458 & 0.338 & & & & \\
\hline & SA & Medium & -0.256 & 0.483 & 0.94 & -3.55 & -2.12 & -2.74 \\
\hline & SS & & -0.294 & 0.659 & & & & \\
\hline & SA & Low & -0.208 & 0.275 & 0.60 & -3.91 & -1.93 & -2.75 \\
\hline & SS & & 0.142 & 0.185 & & & & \\
\hline \multirow{6}{*}{$\begin{array}{l}\text { RMF } \\
\text { (total biomass) }\end{array}$} & SA & High & -0.096 & 0.047 & 0.12 & 1.24 & 2.66 & 1.83 \\
\hline & SS & & 0.217 & 0.383 & & & & \\
\hline & SA & Medium & 0.173 & 0.797 & 0.98 & 1.53 & 3.38 & 2.27 \\
\hline & SS & & 0.16 & 0.397 & & & & \\
\hline & SA & Low & -0.149 & 0.229 & 0.32 & 1.09 & 2.24 & 1.56 \\
\hline & SS & & -0.055 & 0.058 & & & & \\
\hline \multirow{6}{*}{$\begin{array}{l}\text { SMF } \\
\text { (total biomass) }\end{array}$} & SA & High & -0.066 & 0.008 & 0.51 & 1.82 & 3.68 & 2.60 \\
\hline & SS & & 0.234 & 0.296 & & & & \\
\hline & SA & Medium & $<0.005$ & $<0.005$ & 0.29 & 3.80 & 6.05 & 4.83 \\
\hline & SS & & 0.031 & 0.234 & & & & \\
\hline & SA & Low & 0.451 & 0.372 & 0.41 & -5.37 & -2.54 & -3.69 \\
\hline & SS & & -0.039 & 0.006 & & & & \\
\hline
\end{tabular}

seedling types (two-way ANOVA, $\mathrm{F}_{1,84}=1.150, p=0.287$ ), and there was no interaction between nutrient level and seedling type $\left(F_{2,84}=0.823, p=0.443\right)$, but there was a significant difference between nutrient levels $\left(\mathrm{F}_{2,86}=4.609, p=0.016\right)$.

\subsection{Effect of nutrient level on flowering time and seed production of $\mathrm{P}$. thunbergii}

The first flower was observed on 8 September. Flowering time was affected by nutrient level and differed between aerial and subterranean flowers (Fig. 3). Initial flowering at the high nutrient level occurred earlier than at the other levels. Aerial flowers appeared more rapidly than subterranean flowers (Fig. 3).

The number of subterranean seeds was significantly higher than that of aerial seeds (two-way ANOVA, $F_{1,24}=6.342, p<0.05$ ), and the number of seeds increased significantly with increasing nutrient level $\left(F_{2,24}=110.881, p<0.001\right)$. There was no interaction between seedling type and nutrient level $\left(F_{2,24}=1.080\right.$, $p=0.355$ ) (Table 2). The weight of subterranean seeds was significantly greater than that of aerial seeds (PERMANOVA, $\mathrm{F}_{1,24}=5.173$, $p<0.05$ ), and seed weight significantly increased with increasing nutrient level $\left(F_{2,24}=77.836, p<0.001\right)$. There was no interaction between seedling type and nutrient level $\left(F_{2,24}=0.839, p=0.447\right)$ (Table 2).

The number of seeds per biomass differed significantly among nutrient levels for aerial seeds (ANOVA, $\mathrm{F}_{2,12}=25.500, p<0.001$ ) but not for subterranean seeds $\left(F_{2,12}=0.435, p=0.657\right)$ (Fig. $4 \mathrm{a}$ and $4 \mathrm{~b}$ ). At low levels, the number of aerial seeds per biomass was higher than that under the other conditions ( $p<0.05$, Tukey HSD). Aerial seed allocation was significantly increased with increasing nutrient level (ANOVA, $\mathrm{F}_{2,12}=4.646, p<0.05$ ) but not subterranean seed allocation $\left(F_{2,12}=0.213, p=0.811\right)$. This was due to the dissimilar low $(1.2 \%)$ and high $(0.8 \%)$ nutrient levels $(p<0.05$, Tukey HSD) (Fig. $4 c$ and d).

\section{Discussion}

$P$. thunbergii showed a decrease in LMF and an increase SMF and RMF with total biomass, thus during plant growth. This characteristic is similar to that of other plants (Poorter et al., 2012). RGR $R_{S T}$ did not differ between seedling types in the different nutrient treatments, which contradicts our initial hypothesis. We had argued that irrespective of seedling type $P$. thunbergii would be similar to other plant species, which are incapable of high RGR $_{S T}$ at low nutri-

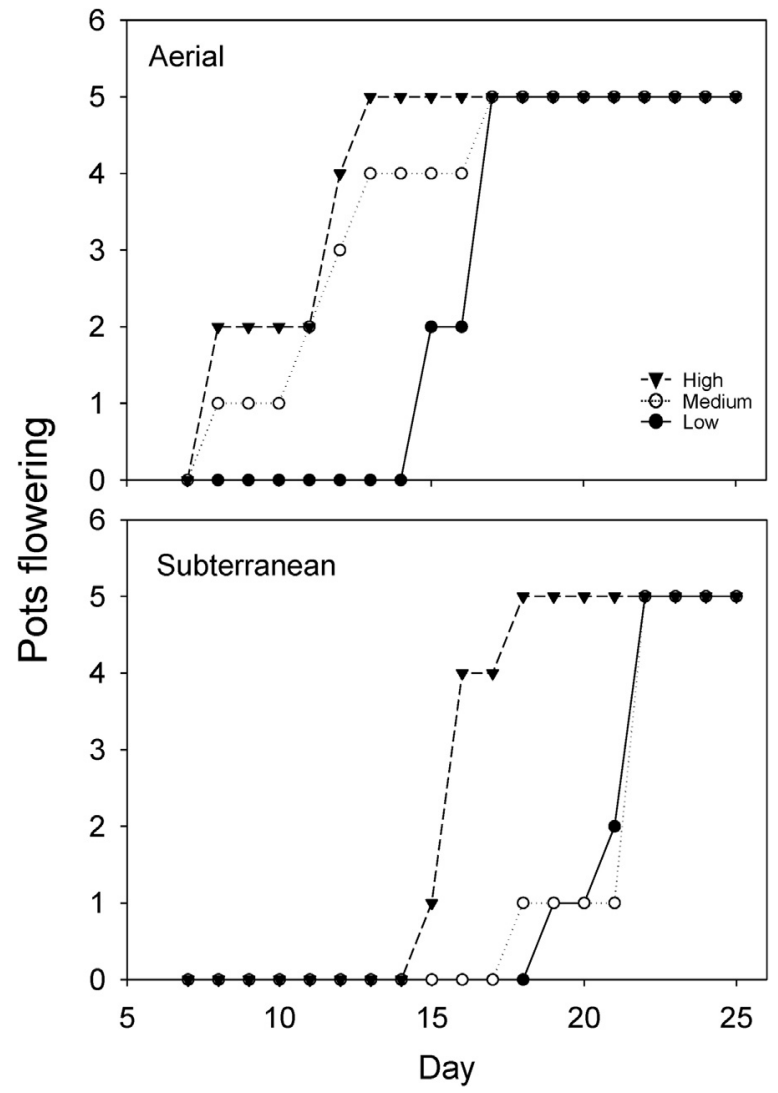

Fig. 3. Persicaria thunbergii flowering time according to nutrient levels. The date on which flowering was observed in the pot was recorded.

ent levels (Chapin, 1980). Choo et al. (2015) reported that biomass allocation differed between SS and SA under flooding and shading conditions. Our results show that biomass allocation to SS and SA did not differ in the different nutrient treatments. Thus, soil nutrient levels apparently had little influence on biomass allocation to SS and SA.

In the annual amphicarpic plant Amphicarpum purshii, Cheplick and Quinn (1982) suggested that the allocation to different plant parts differed between the two seedling types according to soil moisture level, and that these differences were responsible for 
Table 2

Number and weight of seeds in a pot according to nutrient level (average \pm SE, Tukey or permutational pair-wise test; $\mathrm{p}<0.05$ ).

\begin{tabular}{|c|c|c|c|c|}
\hline & Type & High level $(n=5)$ & Medium level $(n=5)$ & Low level $(n=5)$ \\
\hline \multirow[t]{2}{*}{ Number } & Aerial seeds & $1330.8( \pm 135.55)^{\mathrm{a}}$ & $648.4( \pm 34.79)^{\mathrm{b}}$ & $48.2( \pm 12.76)^{\mathrm{c}}$ \\
\hline & Subterranean seeds & $1543.4( \pm 166.48)^{\mathrm{a}}$ & $959.0( \pm 54.68)^{b}$ & $91.8( \pm 14.50)^{c}$ \\
\hline \multirow[t]{2}{*}{ Weight } & Total aerial seeds & $16.379( \pm 1.513)^{\mathrm{a}}$ & $7.169( \pm 0.647)^{\mathrm{b}}$ & $0.418( \pm 0.134)^{c}$ \\
\hline & Total subterranean seeds & $19.197( \pm 2.665)^{\mathrm{a}}$ & $11.319( \pm 1.157)^{b}$ & $1.062( \pm 0.189)^{\mathrm{c}}$ \\
\hline
\end{tabular}

Table 3

SA and SS of LMF, RMF and SMF according to nutrient level (average \pm SE, Tukey or permutational pair-wise test; $p<0.05$ ).

\begin{tabular}{|c|c|c|c|c|c|c|}
\hline & \multicolumn{2}{|l|}{ High } & \multicolumn{2}{|l|}{ Medium } & \multicolumn{2}{|l|}{ Low } \\
\hline & SA & SS & SA & SS & SA & SS \\
\hline LMF & $\begin{array}{l}0.27 \pm 0.02 \\
0.26 \pm 0.01^{b}\end{array}$ & $0.25 \pm 0.02$ & $\begin{array}{l}0.33 \pm 0.03 \\
0.34 \pm 0.01^{\mathrm{a}}\end{array}$ & $0.34 \pm 0.03$ & $\begin{array}{l}0.27 \pm 0.03 \\
0.27 \pm 0.01^{b}\end{array}$ & $0.28 \pm 0.02$ \\
\hline RMF & $\begin{array}{l}0.2 \pm 0.02 \\
0.21 \pm 0.01^{\mathrm{b}}\end{array}$ & $0.2 \pm 0.02$ & $\begin{array}{l}0.18 \pm 0.02 \\
0.18 \pm 0.01^{b}\end{array}$ & $0.18 \pm 0.02$ & $\begin{array}{l}0.26 \pm 0.05 \\
0.23 \pm 0.02^{\mathrm{a}}\end{array}$ & $0.21 \pm 0.03$ \\
\hline SMF & $\begin{array}{l}0.53 \pm 0.03 \\
0.54 \pm 0.01^{\mathrm{a}}\end{array}$ & $0.55 \pm 0.02$ & $\begin{array}{l}0.49 \pm 0.02 \\
0.49 \pm 0.01^{b}\end{array}$ & $0.48 \pm 0.04$ & $\begin{array}{l}0.47 \pm 0.04 \\
0.49 \pm 0.01^{\mathrm{ab}}\end{array}$ & $0.52 \pm 0.03$ \\
\hline
\end{tabular}
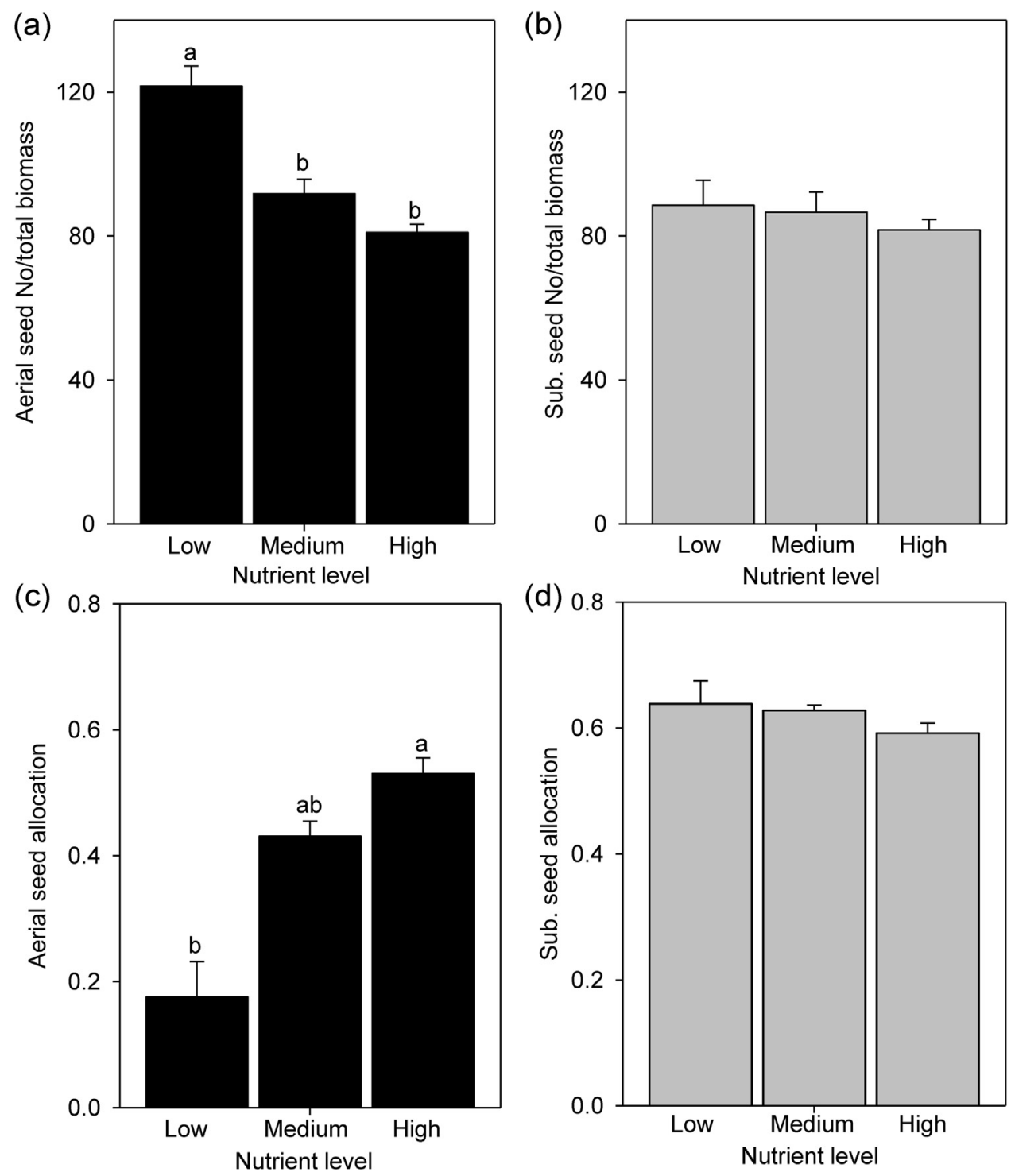

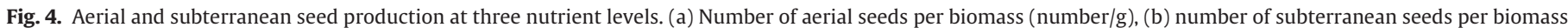
(number/g), (c) aerial seed allocation, and (d) subterranean seed allocation. 
seedlings from subterranean seeds having greater survivorship than seedlings from aerial seeds. P. thunbergii seedlings from subterranean seeds in early growth stages had a survival advantage and a greater number of leaves (Choo et al., 2015). In our study, however, the different seedling types showed similar RGR $_{\mathrm{ST}}$ and total biomass values at first harvest. Thus, the ability to survive or compete under various nutrient conditions did not differ between SA and SS. In addition, this result showed that SA and SS would have similar productivity because plant productivity depends on plant size (Gadgil and Bossert, 1970; Abrahamson and Gadgil, 1973). Amphicarpic plants exhibit a close relationship between the amphicarpy ratio (aerial propagule: subterranean propagule) and the total biomass (Trapp and Hendrix, 1988; Kawano et al., 1990).

Kawano et al. (1990) suggested that soil nutrient and moisture exerted only slight effects on allocation pattern in field $P$. thunbergii. However, in our study the number and weight of the two types of seed increased with increasing nutrient levels; moreover, aerial seed allocation increased with increasing nutrient level in $P$. thunbergii. The previous study (Kawano et al., 1990) was conducted in the field, which complicates determination of the effect of nutrients on reproduction. Habitat conditions, such as nutrient availability, may modulate the amphicarpy trade-off. The observed decline in allocation to aerial seeds combined to the higher number of small aerial seeds produced per biomass under nutrient limitation might reflect a specific plant response that can increase the probability of escape in a detrimental habitat (Cheplick, 1987, 1994). The stability of the subterranean seed allocation and the number of seeds per biomass at all three nutrient levels might reflect a specific plant response that source dispersal increases the likelihood of maintaining mother sites even under unfavorable conditions (Urbanska, 1997).

Most amphicarpic plants developed early to subterranean propagules or flower under various conditions (Zeide, 1978; Cheplick and Quinn, 1982; Cheplick, 1983). In addition, aerial plant biomass production was more dynamic and plastic than subterranean reproductive organ production (Cheplick, 1994). Flooding changed the allocation in $P$. thunbergii to earlier aerial flowering, with potential impacts on the population (Choo et al., 2014). In our study, subterranean flowers did not form earlier than the aerial ones. It is thus more congruent with the findings by Kawano et al. (1990) than those of Choo et al. (2014). We suggested that different evolutionary drivers acted on seed allocation in aquatic amphicarpic ( $P$. thunbergii) and arid amphicarpic plants.

\section{Conclusion}

$P$. thunbergii has an efficient reproductive strategy in insufficient nutrient habitats, which increases the probability of being retained in its mother site using stable productive traits with subterranean seeds and escaping insufficient nutrient habitats by changing the productive traits of aerial seeds. These characteristics would increase the ability of survival at insufficient nutrient conditions. This life-history strategy of $P$. thunbergii is thus different from amphicarpic plants in arid or semi-arid habitats.

\section{Acknowledgements}

This study was supported by Basic Science Research Program through the National Research Foundation of Korea (NRF) funded by the Ministry of Education (NRF-2012R1A1A2001007, NRF2015R1D1A1A01057373), and the Korea Ministry of Environment as "The Eco-Innovation Project, 416-111-010."

\section{References}

Abrahamson, W.G., Gadgil, M., 1973. Growth form and reproductive effort in goldenrods (Solidago Compositae). Am. Nat. 107, 651-661.

Barker, N.P., 2005. A review and survey of basicarpy geocarpy, and amphicarpy in the African and Madagascan flora. Ann. Mo. Bot. Gard. 92, 445-462.

Bloom, A.J., Chapin III, F.S., Mooney, H.A., 1985. Resource limitation in plants-an economic analogy. Annu. Rev. Ecol. Syst. 16, 363-392.

Bray, R.H., Kurtz, L.T., 1945. Determination of total, organic and extracted forms of phosphorus in soil. Soil Sci. 59, 39-45.

Brouwer, R., 1962. Nutritive influences on the distribution of dry matter in the plant. J. Agric. Sci. 10, 399-408.

Chapin III, F.S., 1980. The mineral nutrition of wild plants. Annu. Rev. Ecol. Syst. 11, 233-260.

Cheplick, G., Quinn, J., 1982. Amphicarpum purshii and thepessimistic strategy in amphicarpic annuals with subterranean fruit. Oecologia 52, 327-332.

Cheplick, G.P., 1983. Differences between plants arising from aerial and subterranean seeds in the amphicarpic annual Cardamine chenopodifolia (Cruciferae). Bull. Torrey Bot. Club 110, 442-448.

Cheplick, G.P., 1987. The ecology of amphicarpic plants. Trends Ecol. Evol. 2, 97-101.

Cheplick, G.P., 1994. Life history evolution in amphicarpic plants. Plant Species Biol. 9, 119-131.

Choo, Y.H., Kim, H.T., Nam, J.M., Kim, J.G., 2014. Flooding effects on seed production of the amphicarpic plant Persicaria thumbergii. Aquat. Bot. 119, 15-19.

Choo, Y.H., Nam, J.M., Kim, J.H., Kim, J.G., 2015. Advantages of amphicarpy of Persicaria thunbergii in the early life history. Aquat. Bot. 121, 33-38.

Gadgil, M., Bossert, W.H., 1970. Life historical consequences of natural selection. Am. Nat. 104, 1-24.

Gedroc, J.J., McConnaughay, K.D.M., Coleman, J.S., 1996. Plasticity in root/shoot partitioning: optimal, ontogenetic, or both? Funct. Ecol. 10, 44-50.

Grime, J.P., 2006. Plant Strategies, Vegetation Processes, and Ecosystem Properties. John Wiley \& Sons, New York.

Iwasa, Y., Roughgarden, J., 1984. Shoot/root balance of plants: optimal growth of a system with many vegetative organs. Theor. Popul. Biol. 25, 78-105.

Kamphake, L.J., Hannah, S.A., Cohen, J.M., 1967. Automated analysis for nitrate by hydrazine reduction. Water Res. 1, 205-216.

Kaul, V., Koul, A., Sharma, M., 2000. The underground flower. Curr. Sci. 78, 39-44.

Kawano, S., Hara, T., Hiratsuka, A., Matsuo, K., Hirota, I., 1990. Reproductive biology of an amphicarpic annual, Polygonum thunbergii (Polygonaceae) spatio-temporal changes in growth, structure and reproductive components of a population over an environmental gradient. Plant Species Biol. 5, 97-120.

Kawano, S., 2008. 11: Polygonum thunbergii sieb: et zucc. (Polygonaceae). Plant Species Biol. 23, 222-227.

Kim, D.H., Choi, H., Kim, J.G., 2012. Occupational strategy of Persicaria thunbergii in riparian area: rapid recovery after harsh flooding disturbance. J. Plant Biol. 55, 226-232.

Kim, D.H., Kim, H.T., Kim, J.G., 2013. Effects of water level and soil type on the survival and growth of Persicaria thumbergii during early growth stages. Ecol. Eng. 61, 90-93.

Kim, J.G., Park, J.H., Choi, B.J., Sim, J.H., Kwon, G.J., Lee, B.A., Lee, Y.W., Ju, E.J., 2004. Method in Ecology. Bomoondang, Seoul (in Korean).

Koller, D., Roth, N., 1964. Studies on the ecological and physiological significance of amphicarpy in Gymnarrhena micrantha (Compositae). Am. J. Bot. 15, 26-35.

Masuda, M., Yahara, T., 1994. Reproductive ecology of a cleistogamous annual Impatiens noli-tangere L., occurring under different environmental conditions. Ecol. Res. 9, 67-75.

Murphy, J., Riley, J.P., 1962. A modiped single solution method for the determination of phosphate in natural waters. Anal. Chim. Acta 27, 31-36.

Poorter, H., Remkes, C., Lambers, H., 1990. Carbon and nitrogen economy of 24 wild species differing in relative growth rate. Plant Physiol. 94, 621-627.

Poorter, H., Niklas, K.J., Reich, P.B., Oleksyn, J., Poot, P., Mommer, L., 2012. Biomass allocation to leaves, stems and roots: meta-analyses of interspecific variation and environmental control. New Phytol. 193, 30-50.

Schmid, B., Weiner, J., 1993. Plastic relationships between reproductive and vegetative mass in Solidago altissima. Evolution 47, 61-74.

Schnee, B.K., Waller, D.M., 1986. Reproductive behavior of Amphicarpaea bracteata (Leguminosae) an amphicarpic annual. Am. J. Bot. 73, 376-386.

Solorzano, L., 1969. Determination of ammonia in natural waters by the phenolhypochlorite method. Limnol. Oceanogr. 14, 799-801.

Suzuki, M., Kaya, Y., Ishida, T.A., Hattori, K., Miki, K., Nakamura, T., Kimura, M.T., 2007. Flowering phenology and survival of two annual plants Impatiens noli-tangere and Persicaria thunbergii co-occurring in streamside environments. Ecol. Res. 22, 496-501.

Tilman, D., 1988. Plant Strategies and the Dynamics and Structure of Plant Communities. Princeton University Press, Princeton.

Trapp, E.J., Hendrix, S.D., 1988. Consequences of a mixed reproductive system in the hog peanut, Amphicarpaea bracteata (Fabaceae). Oecologia 75, 285-290.

Urbanska, K.M., 1997. Safe sites-interface of plant population ecology and restoration ecology. In: Urbanska, K.M., Webb, N.R., Edwards, P.J. (Eds.), Restoration Ecology and Sustainable Development. Cambridge University Press, p. 81.

Zeide, B., 1978. Reproductive behavior of plants in time. Am. Nat. 112, 636-639. 